\title{
Agnieszka Bukowska
}

Editor-in-Chief

\section{From the Editor}

I am pleased to give you the latest issue of "Securitologia" (2/2017).

We strive to make our magazine available to the widest possible audience. To achieve it we have made some changes.

Well, all the articles we've included in the current issue are available in English. Some of them, those we have received from authors written in Polish, are available in two language versions. We hope that thanks to such a procedure, "Securitologia" will gain even more interest among both its readers and those who want to publish on its pages.

The current issue is opened by the Education for Security at Polish Universities article. The authors carry out a critical analysis and diagnosis of the state of education for security in Poland in the context of the paradigms of security sciences and European Union standards. In the further part of the issue, the reader will find several articles dealing with police issues.

In the text Organization of the Shooting Training System in the Polish Police, the organization and form of the current training system for the Polish police was presented. Based on the results of previous studies, the author indicates that more important than individual personality traits are training sessions performed by policemen. The introduction of training that would reflect real situations would help to improve the level of police officers' preparation for duty.

Creating the English-language version of the journal "Securitologia" is financed under contract No. 724/P. DUN/2018 from the funds allocated by the Minister of Science and Higher Education for dissemination of science. 
The article Exploring Lay People's Views on the Polish Police, presented selected results of doctoral research on the views of the Polish police in the sociological context before and after political changes that took place in Poland in 1989.

What about this Police? This is a text referring to the transformation of police education in the era of systemic changes and it points to the still-current problem of creating a coherent HR policy, placing special emphasis on the importance of creating leadership in the police.

The problem of police reform in France is presented in the article Police Reforms in France: 40 Years of Searching for a Model. The author notes that despite various reforms, it still has a working style primarily based on aggressive methods, in which identity checks and arrests are the main tools used on a daily basis. Another problem is the lack of evaluation of the effectiveness of security policies in institutions where the professional culture is unfavorable to science and any external points of view.

In turn, the analysis of security procedures in large area stores and the security of large shopping centers, which are one of the most sensitive soft targets susceptible to attacks with both firearms and various types of white weapons, and especially knives is presented in Big Shopping Centers as Objects of Potential Terrorist Attacks.

In the Indigeneity Discourse within the Kurdish Political Movement the author addresses the issue of Kurdish ethnic minority in The Middle East. He presents research aimed at drawing attention to the core aspect of the Kurds by examining self-identification as part of the Kurdish political movement in Turkey.

The security aspects and the process of violating and building the foundations of human rights in areas previously covered by armed conflicts are explained in the article $H u$ man Rights Violations in Post Conflict Areas as a Threat to Peace and Security: a Mission in Kosovo.

For those who want to become familiar with crisis response operations, we have the article International Security and Defense - The Example of NATO Operations.

How can you counteract threats to social security through sport? Many important topics devoted to various aspects of counteracting threats to social security through physical activity can be found in the article Physical Activity as a Factor Guaranteeing Social Security.

I would like to thank all reviewers who have done their job and made their comments voluntarily, without any remuneration.

I wish you a pleasant and fruitful reading! 